\title{
AMÉRY FREUD: REFLEXIONES COMPLEMENTARIAS SOBRE EL SURGIMIENTO DE LA CONCIENCIA DE CULPA Carlos Alfonso Garduño*
}

RESUMEN: En el presente texto se realiza un análisis de los reclamos de justicia del ensayista austriaco y víctima del nazismo, Jean Améry, a la luz de los desarrollos del psicoanálisis freudiano, con el fin de ofrecer un marco conceptual que nos ayude a comprender y valorar su propuesta ética.

PALABRAS CLAVE: Jean Améry, Freud, culpa, resentimiento, tabú.
ABSTRACT: In this article, we analyze the call for justice from Austrian essayist and Nazi victim, Jean Améry, in light of of the Freudian psychoanalytical developments, in order to provide a conceptual framework with which to understand and value his ethical proposal.

KEYWORDS: Jean Améry, Freud, guilt, resentment, taboo.
RECEPCIÓN: 11 de enero de 2011.

ACEPTACIÓN: 6 de septiembre de 2012.
* Ciencias Sociales, Universidad Panamericana. 


\section{AMÉRY FREUD: REFLEXIONES COMPLEMENTARIAS SOBRE EL SURGIMIENTO DE LA CONCIENCIA DE CULPA}

En el pasaje del rio/ es dificil saber/dónde comienza el rio;/ dónde comienza/ en el río el fango;/ dónde la tierral empieza en el fango;/ dónde el hombre,/dónde la piel/ comienza en el fango;/ dónde comienza el hombre/ en aquel hombre. El perro sin plumas.

JoÃo CABRAL DE MELO

uando Jean Améry ${ }^{1}$ expresa su resentimiento con el fin de reivindicar

${ }^{1}$ Seudónimo que el ensayista austriaco Hans Maier utiliza para desligarse de sus raíces culturales alemanas y vincularse con los principios del pensamiento político y filosófico francés. Nacido en Viena en 1912, de padre judío, muerto en combate durante la Primera guerra mundial, y de madre católica, que lo educó bajo los preceptos de dicha religión, durante la Segunda guerra mundial formó parte de la resistencia en Bélgica, distribuyendo propaganda antinazi. Ahí fue capturado y torturado. Posteriormente, fue remitido bajo la clasificación de "judío" a los campos de concentración de Auschwitz, Buchenwald y Bergen-Belsen, en los que se le forzó a realizar labores físicas. En 1945, fue liberado de este último campo por el ejército británico. A partir de entonces, dedicó su obra a reflexionar sobre sus vivencias en relación al Holocausto. Sus libros más significativos al respecto son Más allá de la culpa y la expiación: tentativas de superación de una víctima de la vio- la posición ética de la víctima y la responsabilidad del culpable, expresa a su vez un malestar y una insatisfacción, ocasionados por el actual orden social y cultural, con respecto a la injusticia que sufrió, en tanto víctima del nazismo, torturado y sometida en campos de concentración. Los textos de Améry son, antes que una reflexión filosófica, un reclamo personal. Toda su argumentación parte de su situación existencial; de sus sentimientos de disgusto ante un contexto

lencia; Revuelta y resignación: Acerca del envejecer y Levantar la mano sobre uno mismo: discurso sobre la muerte voluntaria. En 1978, Améry se suicidó tomando una sobredosis de píldoras para dormir. 
que parece haber olvidado su sufrimiento y el de millones de víctimas; pero, sobre todo, de la marca indeleble que dejó el abuso sufrido y de la imposibilidad de reencontrar su dignidad en una sociedad que marcha hacia el futuro sin reparar las injusticias del pasado. Mi interés por la propuesta de Améry surge de esta peculiar forma de reflexión sobre la ética y la justicia, que se basa por completo en las exigencias de una víctima concreta, llenas de resentimientos, como todo reclamo del mismo tipo.

A mi parecer, las reflexiones freudianas sobre el origen de la ética y sobre las conflictivas relaciones entre los deseos de satisfacción de los individuos y las prohibiciones de la cultura nos ofrecen un marco ideal para comprender un tipo de pensamiento como el de Améry, puesto que la teoría psicoanalítica centra su actividad en la dilucidación de los principios que permiten que, a partir del análisis de nuestros deseos y afecciones más originarios, seamos capaces de comprender la génesis de nuestras creaciones culturales - entre las que se encuentra la ética- y sus consecuencias. Así pues, aquí propongo hacer un análisis del texto de Améry titulado "Resentimientos", ${ }^{2}$ a la luz

${ }^{2}$ Jean Améry, "Resentimientos", en Más allá de la culpa y la expiación: tentativas de superación de una víctima de la violencia, 2004, Valencia, Pretextos. de los conceptos desarrollados por Freud en torno al origen del comportamiento ético y el malestar que éste produce en los individuos, a quienes se exige renunciar a su satisfacción en pos de un supuesto bien común; un bien que, en realidad, nunca es capaz de beneficiar a todos los individuos.

Comencemos, pues, por exponer los principales reclamos y conceptos de Améry que analizaremos por medio de los desarrollos del psicoanálisis freudiano, no con el fin de psicoanalizarlo, sino de ampliar la comprensión de su discurso con miras a aumentar nuestros criterios de valoración.

Por principio de cuentas, Améry se califica a sí mismo bajo la denominación convencional de "víctima del nazismo" y desde esa posición construye todo su discurso. A su parecer, el pueblo al que interpela directamente, el alemán -aun cuando su discurso en realidad interpela a cualquier lector- muestra escasa comprensión de su condición y ello le provoca no sentirse a gusto en dicho país, a pesar de todas las cortesías que éste le presta. La principal causa que identifica Améry de su malestar, más allá de las terribles marcas que conserva por el maltrato sufrido, las cuales le impiden reencontrar su lugar en la sociedad, son los resentimientos que sobreviven en él, pues 
considera que los criminales que en el pasado abusaron de su persona ahora gozan de todas las oportunidades para realizar sus vidas y envejecer con dignidad, sin ningún tipo de represalia. El objetivo de su texto, por tanto, es describir su condición subjetiva de víctima, para dar testimonio de su sufrimiento en primera instancia y para hacernos comprender, si es posible, la injusticia que representa el contexto actual, mediante el análisis introspectivo de su resentimiento, entre otras afecciones.

Para Améry, su condición es condenada tanto por moralistas como por psicólogos. Estos no consideran aceptables ni sus sentimientos ni sus reclamos. Sin embargo, el autor insiste en defender su posición, puesto que para él, sus resentimientos son el fruto de una larga evolución personal e histórica que vuelve legítima su exigencia. Améry no acepta perdón ni reconciliaciones con el pasado, sino restitución de lo que le fue arrebatado, la aceptación de la culpa del pueblo alemán y el castigo sobre los responsables.

Sin embargo, resulta que los alemanes también se sentían víctimas por las consecuencias del Tercer Reich; y ellos sí decidieron renunciar a todo rencor contra la resistencia y los judíos: “¿Cómo podíamos aún dirigirles a aquellos tipos exigencias de reparación?”. ${ }^{3}$ Es decir, ¿cómo puede un

${ }^{3}$ Ibid., p. 146. alemán que ha decidido olvidar, aunque esté en su derecho de perdonar por su propio sufrimiento, comprender el sufrimiento y la exigencia de quien conserva su resentimiento como condición existencial y reclamo de justicia? Para ellos, Améry es incomprensible; es un ser afectado, deformado bajo sus parámetros de normalidad. ¿Por qué? Porque Améry no es capaz, como ellos, de ver al futuro y dejar atrás el pasado. Améry se encuentra instalado en el estado contradictorio que exige que se revierta lo irreversible, que se cancele lo acontecido. Estado elegido por él porque olvidar le "resulta tan costoso como demasiado fácil a los perseguidores del ayer". ${ }^{4}$ No desea convertirse en un cómplice de sus actos, sino que "se nieguen a sí mismos" $\mathrm{y}$ lo acompañen en su propia negación; que acepten su culpa, su responsabilidad y las consecuencias de sus actos. Busca "la resolución del conflicto irresuelto en el campo de la acción de la praxis histórica". ${ }^{6}$

La conflictiva situación de Améry, sumamente patológica, realmente parece exigir lo imposible. Empero, lo mantiene la convicción de poseer la verdad moral de su conflicto; sabe que la víctima es el testimonio de la verdad, en tanto punto de partida del

${ }^{4}$ Ibid., p. 149.
${ }^{5}$ Ibidem.
${ }^{6}$ Ibid., p. 150. 
que se puede emprender el acto de justicia. Su deseo lo opone al presente factual y cierra sus posibilidades de realización futuras; pero él se mantiene en su discurso por defender su individualidad contra la disolución en el cauce colectivo. De hecho, al hablar de "culpa colectiva" del pueblo alemán, se coloca a sí mismo más allá de lo que la sociedad está dispuesta a aceptar. En otras palabras, Améry ha violado las convenciones sociales, enfrentándose a ellas en un reclamo de justicia, el cual, sin embargo, parece ser contraproducente, puesto que la carga de la culpa es llevada completamente por él y no por los culpables -el pueblo alemán considerado globalmente-: "la culpa colectiva pesa sobre mí, no sobre ellos. El mundo que perdona y olvida me ha condenado a mí, no a aquellos que asesinaron o consintieron el asesinato". ${ }^{8}$

Lo que le queda a Améry es conservar su "anhelo individual de reversibilidad de los procesos irreversibles" y esperar algún resultado, "logrando que en un bando se conserve el resentimiento y en el otro se despierte, gracias a este afecto, una actitud de desconfianza respecto a sí mismos". ${ }^{10}$ Se trata, pues, de una lucha ideoló-

\footnotetext{
${ }^{7}$ Ibid., p. 154.

${ }^{8}$ Ibid., p. 158.

${ }^{9}$ Ibid., p. 160.

${ }^{10}$ Ibid., p. 161.
}

gica en la que el resentimiento es la clave del éxito. Pero Améry no es muy optimista respecto al resultado, ya que nadie parece aceptar su discurso excepto los medios de comunicación, los cuales lo compran y lo convierten en una mercancía más que circula en el sistema productor que ha decidido olvidar y ver sólo hacia las ganancias futuras. Su resentimiento es transformado, al ser absorbido por la sociedad, en entretenimiento. ¿Cómo podemos concebir que un hombre conserve un afecto que a todas luces resulta ser desventajoso, con el fin de defender una causa que parece estar destinada al fracaso, al menos en el contexto actual? ¿Qué sentido tiene conservar el resentimiento a toda costa y mantener la posición de la víctima?

Me parece que la obra de Freud, en relación a la formación del comportamiento ético, nos puede ofrecer algunas respuestas a estos cuestionamientos y nos puede ayudar a valorar de mejor manera la propuesta de Améry. Para ello, comenzaremos por Tótem y Tabú, a propósito del comentario de Améry de que la "culpa colectiva" es un "término casi tabú". ${ }^{11}$ La obra en cuestión aborda el tema del origen de la religión y la moralidad a partir de los conceptos de tabú, como prohibición primordial, y de totemismo, como uno de los primeros

${ }^{11}$ Ibid., p. 154. 
modos de organización social. El término tabú designa una prohibición en relación a dos sentidos contrapuestos: lo sagrado y lo impuro. Evidentemente, lo opuesto al tabú es lo acostumbrado y asequible a todos.

Que Améry refiera a la culpa colectiva como un tabú, como un tema que es prohibido tocar, es un aspecto sintomático del funcionamiento del pueblo alemán; nos indica que la aceptación de la culpa que Améry reclama se opone a la cotidianidad que ha establecido dicho pueblo. Por otro lado, el tabú no es una restricción ni religiosa ni moral; simplemente, su origen es desconocido, carece de fundamentación y parece cosa natural. Lo que nos dice Freud sobre ello es que seguramente es anterior a los sistemas morales y religiosos, por ser una forma primitiva de ellos. Que la culpa colectiva haya caído en la categoría de tabú nos indica que ella resulta amenazante, por su sacralizad o su impureza, y por ello hay que prohibirla, de manera que su ausencia sea algo natural. En el caso que nos interesa, ¿por qué aceptar la culpa es tan amenazante? ¿Acaso el hecho de que el crimen cometido salga a la luz haría cambiar el orden de las cosas, tal como Améry pretende? ¿Y de qué manera podría cambiar las cosas, si el significado de tabú es ambivalente en realidad?
Dos aspectos del tabú llaman mi atención "El tabú violado se vengaba a sí mismo" 12 "quien ha violado el tabú, por ese mismo hecho se vuelve tabú". ${ }^{13}$ En este sentido, Améry parecía ser un hombre tabú; un hombre que fue a la vez rechazado como un enfermo, un impuro, y considerado una especie de hombre sagrado que recorre Alemania propagando su mensaje, sin ser equiparado en ningún momento a los demás miembros de la sociedad, aislado y admirado por su situación extraordinaria y a la vez peligrosa. Améry era tratado como si su contacto causara horror. Su verdad se venera y a la vez se aborrece. Ante este panorama, el proyecto de Améry parece estar destinado al fracaso. Sin embargo, la investigación de las motivaciones psíquicas detrás del tabú, nos revela que tal vez no es así. El significado del tabú es ambivalente porque la actitud de los sujetos ante aquello prohibido no fue originalmente de rechazo, sino de deseo. Si algo está prohibido por ser amenazante, se debe a que en realidad es deseado; ello es lo que en verdad lo vuelve peligroso y potencialmente revolucionario.

${ }^{12}$ Sigmund Freud, “Tótem y Tabú”, en Obras completas XIII, 2004, Buenos Aires, Amorrortu editores, p. 29.

${ }^{13}$ Ibidem. 
Ahora bien, el hecho de que el deseo haya sido reprimido, implica que ha sido mandado al olvido; es decir, mientras la prohibición es consciente, el deseo es inconsciente. ¿Podríamos pensar, entonces, que aquello irreversible que Améry intenta revertir, no es sólo el pasado, sino el deseo inconsciente de justicia de sus contemporáneos? ¿Será que en realidad existe tal deseo o estamos especulando de más? Si el deseo sobre el que especulamos existe, lo que Améry hace es recordar al pueblo alemán su deseo inconsciente y a la vez lo induce a violar la prohibición. No olvidemos que el sentimiento que está en juego en la argumentación de Améry es el resentimiento. ¿Qué tantos alemanes sienten ese mismo sentimiento o albergan en sí reclamos de justicia? El número de posibles víctimas, del nazismo y de otras injusticias, podría ser más elevado de lo que Améry cree. La aceptación de la culpa del pueblo alemán bien puede ser considerada como el deseo propio de quienes se sienten víctimas de tal entidad. Antes de aceptar esta conclusión provisional, sigamos repasando los motivos del tabú.

La prohibición que significa el tabú, como mencionamos antes, surge ante un peligro que amenaza el orden social. Sin embargo, tal peligro, según la teoría freudiana de la horda primor- dial-inspirada por Darwin- fue identificado tan sólo después de haber sido perpetrado un crimen: el asesinato del padre. La teoría nos dice que los hermanos de la horda primordial decidieron unirse para matar al padre y derrocar su tiránico mandato, el cual acaparaba para él todos los placeres. Después de cometer el asesinato, movidos por el arrepentimiento, ya que sus emociones hacia el padre eran ambivalentes -tiernas y hostiles, de envidia y temor a la vez- los hermanos decidieron nunca volver a repetir el crimen, estableciendo su prohibición. Freud nos dice que para expiar su culpa, los hermanos devoraron el cadáver del padre con el fin de consumar su identificación con él e interiorizar su autoridad, instaurando el sentimiento de culpa: "el muerto se volvió aún más fuerte de lo que fuera en vida". ${ }^{14}$ Con ello:

La sociedad descansa en la culpa compartida por el crimen perpetrado en común; la religión, en la conciencia de la culpa y el arrepentimiento consiguiente; la eticidad, en parte en las necesidades objetivas de esta sociedad y, en lo restante, en las expiaciones exigidas por la conciencia de culpa. ${ }^{15}$

A partir de la teoría freudiana del surgimiento de la culpa, salen a relu-

${ }^{14}$ Ibid., p. 146.

${ }^{15}$ Ibid., p. 148. 
cir nuevos aspectos que cuestionan la especulación que realizábamos. Si lo propio del tabú es evitar la repetición del crimen y permitir la instauración de la culpa, ¿por qué pareciera que en el caso de Améry la culpa misma es aquello que se prohíbe y no el correlato del tabú? Por otra parte, si el crimen es el antecedente de la culpa, entonces ¿Améry está tratando de restituir el lugar del padre-víctima, esta vez como fundamento de la eticidad? Sobre la primera cuestión, me parece que el tabú y la culpa no se han instalado con respecto al crimen tal como la teoría freudiana explica, porque el pueblo alemán no generó o, en todo caso, superó con facilidad los sentimientos de arrepentimiento; porque la víctima asesinada no provocó en sus victimarios la suficiente ambivalencia -como en el caso del padre- para generar la reacción que pudiera engendrar la culpa. Siendo así, y retomando la segunda pregunta, lo que le queda a Améry es insistir en la necesidad de reconocer que, aun cuando las víctimas del nazismo no generan en el pueblo alemán los sentimientos que el padre en la horda primordial, éstas deberían mover a los alemanes a sentir culpa colectiva porque de igual manera se cometió un crimen que no debería repetirse nunca. Así, curiosamente, aunque lo que mueve a Améry es un sentimiento, su discurso más bien parece apelar a la razón del pueblo que debería sentir culpa en lugar de lo que en realidad siente, que es rechazo por lo que Améry simboliza.

Una situación similar es representada por Freud en su texto Moisés y la religión monoteísta. Bajo la hipótesis de que hubo dos Moisés y que el primero fue un egipcio que intentó establecer una nueva religión con pretensiones universales en Egipto, la cual no fue aceptada, Freud pretende explicar cómo este personaje escogió entonces a los judíos como su pueblo elegido para que llevaran a cabo sus preceptos. Sin embargo, este primer Moisés sufrió la misma suerte que el padre primordial. Tiempo después surgió otro líder, un sacerdote madianita, al cual la tradición igualó con la figura del Moisés egipcio, fusionando las religiones de ambos personajes.

Lo que resulta interesante de esta especulación para nuestro tema es, por un lado, el rechazo de una o varias colectividades hacia una idea ética, incluso cuando parece racionalmente adecuada; y por otro lado, que la naturaleza traumática del asesinato de Moisés sólo afectó a una parte del pueblo judío, por lo cual el sentimiento provocado no podía ser generalizado, a pesar de estar presente en la fusión que realizó la tradición. A esto hemos de agregar la existencia de un periodo de latencia entre el momento del 
hecho traumático y la aparición de los síntomas en la sociedad.

Lo que realmente nos ubica en el centro de la teoría psicoanalítica es que en realidad nada puede ser olvidado en estricto sentido, sino tan sólo reprimido; con el paso del tiempo se encontrará algún tipo de manifestación. En el caso del crimen, si bien no todas las partes de una colectividad se sienten afectadas por él (en tanto víctimas o culpables) y algunas rechazan reclamos como el que realiza Améry, el papel de la tradición jugará un papel fundamental en su conservación y caracterización.

En el caso del crimen de Moisés, por ejemplo, fue la tradición historiográfica del pueblo egipcio, heredada por el judío, lo que permitió que el crimen sobre el Moisés egipcio permaneciera en estado latente y que, con el paso del tiempo, encontrara un lugar dentro del sistema ético de la religión monoteísta. Gracias a ello, la culpa pudo ser instaurada en la ética judía, según la versión freudiana, aunque no se reconoció como tal el crimen.

Por supuesto, esto es apenas una parte de lo que hubiera querido Améry; sus textos, en tanto que pertenecen a una tradición que pretende preservar la memoria de las víctimas, quizás en algún momento sean capaces de generar en la colectividad heredera de quien cometió los crí- menes, los síntomas y la culpa necesarios para lograr la expiación y la actitud moral adecuada.

Pero esto no cumple con todo lo que pide Améry. Freud reconoce que el trabajo de la tradición, aun cuando en parte implica un proceso de conservación de la memoria, también implica uno de deformación, en tanto que parte de su contenido ha caído bajo represión a causa de su carga afectiva. El rumbo que tales deformaciones tomen, dependerá de las circunstancias de recepción y de transmisión de los discursos de la tradición. De ahí la preocupación de Améry de ser utilizado como mercancía por los medios de comunicación. Bajo ese manejo, sus ideas, en tanto que involucran una fuerte carga afectiva, bien pueden causar el efecto contrario al pretendido por el autor. Como nos dice Freud, el reconocimiento de un mismo crimen puede causar actitudes opuestas en relación a la aceptación de la culpa, como en el caso del cristianismo con respecto al judaísmo: "Nosotros [...] hemos hecho lo mismo [asesinar al padre], pero lo hemos confesado, y desde entonces quedamos sin pecado". ${ }^{16}$

La complejidad de la realidad social, histórica y cultural concreta de cada contexto, vuelve muy complicado establecer hasta dónde una pro-

${ }^{16}$ Sigmund Freud, "Moisés y la religión monoteísta”, en Obras completas XXIII, 2002, Buenos Aires, Amorrortu editores, p. 87. 
puesta ética será promovida con éxito. El mero análisis y discusión de las ideas de Améry en abstracto, es decir, en tanto sistema filosófico, nos dice realmente muy poco sobre su viabilidad. En cambio, si se analizan como un proyecto de aplicación concreta, me parece que su valor puede ser establecido con mayor claridad. Así, lo que tal análisis debería tomar en cuenta son aquellos factores que en una situación específica favorecen o no la adopción de cierta actitud ante un crimen, como el cometido por el nazismo, y una parte del pueblo alemán. Y dichos factores, en mi opinión, fueron desarrollados, en parte, por Freud, en El malestar en la cultura.

En dicha obra, se trata el problema del conflicto entre la adopción de las exigencias éticas y la renuncia a satisfacciones. Vivir bajo el dominio de la cultura, para la mayor parte de los individuos, significa, en general, sacrificar más satisfacciones de las que se obtienen. La cultura se funda sobre la represión y su consecuente renuncia pulsional. Sin embargo, los individuos lo aceptan porque, al unirse, crean sistemas de justicia que les brindan la seguridad de que la libertad de sus semejantes no quebrantará la voluntad colectiva. Así, lo que le queda a cada quien es intentar establecer, por medio de los medios de que dispone y de su talento personal, un equilibrio acorde a las exigencias individuales y las demandas culturales de la masa. El problema ante el que se enfrenta la cultura es que, generalmente, los medios y el talento resultan insuficientes y los individuos no reciben compensación por acatar los preceptos culturales. Su malestar, entonces, los lleva a rivalizar con la cultura.

Para el tiempo en que Freud escribió El malestar en la cultura, ya había postulado dos tipos distintos de pulsión, cada uno con diferentes metas: las pulsiones eróticas con meta sexual y las de muerte cuyo fin es la agresión. La inhibición a la que son sujetos los individuos por parte de la cultura debe intentar moderar ambos tipos de pulsión, tanto para limitar las posibilidades de satisfacción, estableciendo un sistema económico para ello, como para prevenir la liberación de la violencia. El proceso psíquico mediante el cual un individuo vuelve inocuo su gusto por la agresión es la introyección de ésta hacia el yo y la posterior contraposición de éste como superyó y como "conciencia moral". La tensión o la violencia que el superyó genera sobre el yo, en lugar de permitir que el yo ejerza tal violencia hacia el exterior, es la llamada "conciencia de culpa", la cual se exterioriza como necesidad de castigo. En este contexto, no es necesario 
que se haya cometido o no un crimen anterior a la instauración de la culpa, pues ésta es más bien "la expresión del conflicto de ambivalencia, de la lucha eterna entre Eros y la pulsión de destrucción o de muerte". ${ }^{17}$

Si lo que Améry pretendía es que en el pueblo alemán se instaure una conciencia de culpa tal que genere la tensión suficiente, no sólo para que la agresión que llevaron a cabo los nazis no se vuelva a repetir, sino para que mueva al pueblo a resarcir los daños y a castigar a los culpables, la cantidad de energía interiorizada y contrapuesta al yo en forma de superyó debería ser de una magnitud semejante a aquella que los individuos estarían dispuestos a ejercer al exterior en caso de que el proceso de inhibición no fuera exitoso. En este sentido, la cantidad de energía utilizada en la instauración de la conciencia de culpa parece ser proporcional a la represión a la que son sometidos los sujetos y a su consecuente capacidad de satisfacción. En otras palabras, la exigencia o aceptación de una culpa, en tanto tensión producida por la introyección de agresión y por la represión de los deseos, parece depender directamente de las posibilidades de satisfacción que pueda ofrecer una cultura específica en cierto momento histórico.

\footnotetext{
${ }^{17}$ Sigmund Freud, "El malestar en la cultura" en Obras completas XXI. 2004, Buenos Aires, Amorrortu editores, p. 128.
}

Una sociedad cuyos preceptos culturales ofrecen variadas posibilidades de satisfacción sentirá una menor tendencia no sólo a la agresión exterior, sino a la interior, es decir, a los sentimientos de culpa. Si lo que sucede en Alemania, como nos dice Améry, es que ahí más bien se respira un ambiente de progreso y modernidad, que se trata de un bello país lleno de gente amable, eso significa entonces que tal sociedad cuenta con pocas posibilidades de aceptar sus reclamos. Empero, el mismo Améry es un testimonio de que el malestar en Alemania no está erradicado. La tensión, la conciencia de culpa, la agresión introyectada, la insatisfacción, se manifiesta en las víctimas. ¡He aquí la verdadera paradoja de la cultura, de la cual nos hace conscientes el resentimiento de Améry!

El supuesto sistema de justicia que ha establecido la cultura alemana no se salva del malestar que Freud identifica y que Améry denuncia. El reclamo de Améry es el de un individuo que ha tenido que sufrir las penas, primeramente, de un pueblo que desbordó su agresión sobre el grupo en el que fue clasificado $y$, posteriormente, de una cultura que le niega la posibilidad de satisfacción después de que ella misma, bajo el influjo de una generación que en el pasado detentó el poder, determinó su condición actual. Améry, por tanto, es un 
insatisfecho que tiene razones para no cambiar su condición subjetiva y exigir, en cambio, que sea la cultura la que sufra modificaciones; que se adopte un nuevo modo de enfrentar la responsabilidad; que se establezca una nueva dinámica pulsional, en tanto que varios miembros de la sociedad, como él, no obtienen lo que en su legítimo derecho deberían obtener.

Améry, como el Moisés de Freud, obtuvo pocos resultados en su intento de reformación ética de la sociedad, al menos mientras vivió. Sin embargo, su obra puede ser difundida y pasar a formar parte de una tradición que, a pesar de no ser la dominante, paulatinamente se podrá abrir camino en tanto representante de mociones olvidadas o, mejor dicho, reprimidas, de gran importancia psíquica. El resentimiento de Améry no desaparecerá en el tiempo ni pasará desapercibido porque la magnitud del crimen que lo originó es enorme. Quizá, como apuntó Freud en su texto sobre Moisés y la religión monoteísta, estamos pa- sando por un período de latencia en el cual los síntomas aún no se manifiestan de manera clara. Mientras tanto, tan sólo queda seguir insistiendo sobre la aclaración de las deudas del pasado, tal como lo hacen Améry y Freud, cuyas obras, bajo esta perspectiva, son complementarias $\mathrm{y}$, discutiblemente, persiguen fines análogos: sanar los malestares que han dejado los hechos traumáticos del pasado.

Como dice W. Benjamin, "el pasado contiene un índice temporal que lo remite a la salvación"; ${ }^{18}$ la dificultad, sin embargo, siempre está en que las circunstancias son demasiado complejas como para esperar que el pasado pueda simplemente ser aclarado. El presente y el futuro están engarzados a él de manera tal que parece imposible determinar hasta qué punto estas dimensiones temporales se están deformando entre sí. Y a ello hemos de agregar los deseos, afectos, compromisos e intereses de todos los involucrados en el proceso que nos podría llevar a una justicia efectiva.

\footnotetext{
${ }^{18}$ Walter Benjamin, Tesis sobre filosofía de la historia, 1977, México, Premia editores, La nave de los locos, p. 112.
} 